\title{
Role of Earth Observations Data in Petroleum and Natural Gas Studies
}

\author{
K Vinod Kumar and PVN Rao* \\ Remote Sensing Applications Area, Indian Space Research Organisation, India
}

*Corresponding author: PVN Rao, Remote sensing applications area, National Remote Sensing Centre, Indian Space Research Organisation, Hyderabad, India.

Submission: 㭗January 27, 2018; Published: 監 February 07, 2018

\section{Introduction}

Earth observation especially remote sensing and communication plays an important role in the petroleum industry. The following are the major areas where it has its applicability

i. Reconnaissance geologic and geophysical surveys/ studies (including gravity-magnetic data)

ii. Satellite communications and data transfer: this includes data transfer from offshore platforms, drilling rigs etc, onshore control centres for offshore activities, monitoring real time drilling operations and virtual reality centres to receive and visualise data.

iii. General positioning and navigation applications, including staking of well locations prior to drilling and planning seismic surveys using Differential GPS data.

iv. Environmental Impact Assessment (EIA) and Natural Hazard studies

v. Digital Elevation Models (DEMs) for topographic analysis based on various types of remote sensing data

vi. Surveillance data of offshore installations from Vessel and Air Traffic Monitoring System (VATMS), CCTV, etc.

Satellite remote sensing especially high resolution data and advanced image analysis of microwave data (polarimetry/ InSAR and DInSAR) from RISAT/ RADARSAT/ TERRASAR satellites with Synthetic Aperture Radars onboard, etc is useful for static and dynamic modelling of surface elevation for use in exploration (topographic displacement, fault / lineament detection), environmental monitoring (oil spills/ slicks detection). Deployment of Hyperspectral Remote Sensing (Imaging) Instrument (with dedicated spectral range selection is useful for detection of seeping hydrocarbons and lithological/ mineralogical identification/ mapping) as well as specialized drones on which such sensors can be mounted for low-altitude surveying will be of immense help in hydrocarbon exploration.

Multispectral image provides a synoptic overview of the terrain which is useful for deciphering the regional geological features like geomorphology and structures. Oil bearing geological structures which are deep seated may have its signature in the regional geological features. In the North Eastern part of India which is rich for oil and gas bearing formations, some of the regional structures especially anticline hill and synclinal valleys are well mapped from the satellite data (Figure 1)

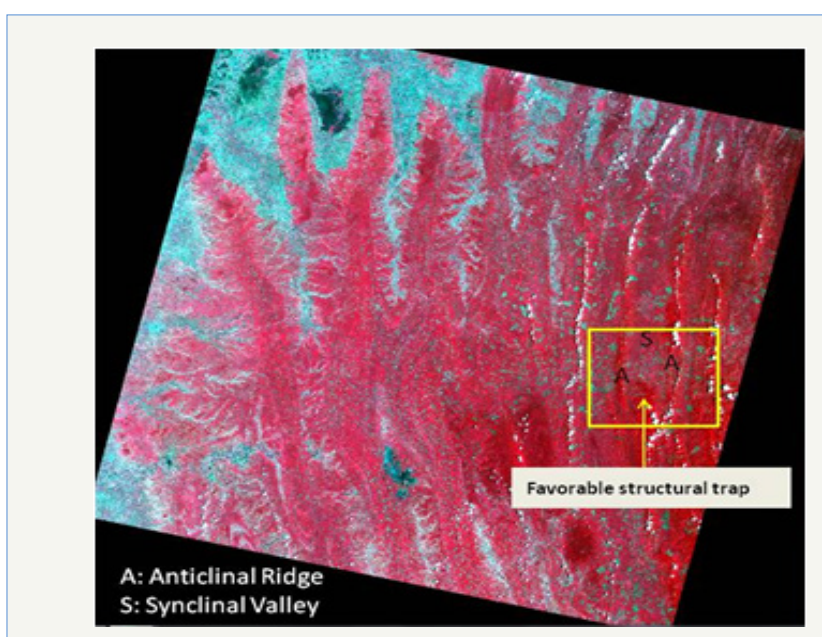

Figure 1: Regional Structural features in Tripura Fold Mountain (NE India) showing the favourable structural trap for gas formations (IRS-LISS-3 FCC (432).

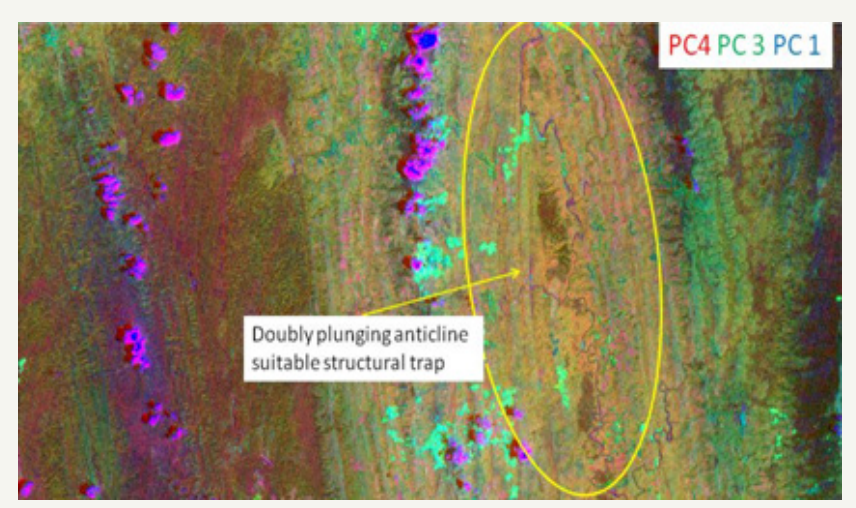

Figure 2: Principal component transformation of IRSLISS-3 data highlighting the proxy geological structures favourable for subsurface oil trap in Tripura folds belts, NE part of India. 
Suitable digital image processing especially statistical techniques like principal component analysis (is a statistical procedure that uses an orthogonal transformation to convert a set of observations of possibly correlated variables into a set of values of linearly uncorrelated variables called principal components) of the multispectral satellite data further enhances the local structural features for detail geophysical survey (Figure 2).

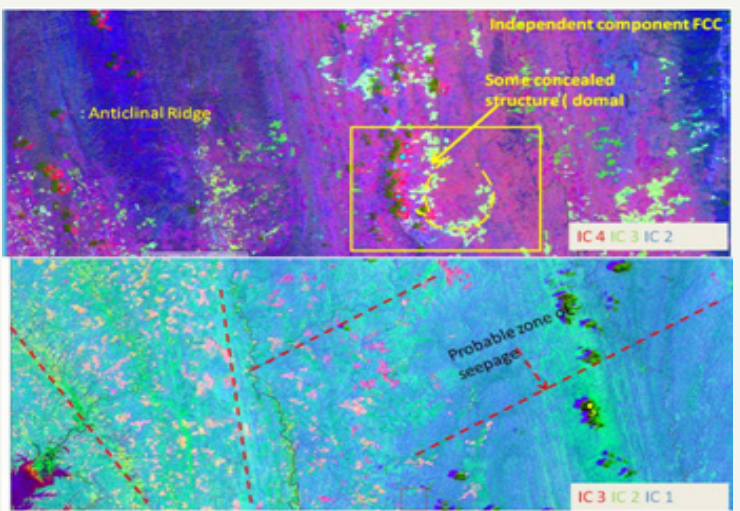

Figure 3: Independent component analysis of IRS-LISS-3 data showing geomorphic anomaly and regional fractures/ faults for Tripura Fold belts which are proxy to subsurface oil bearing formations.

Some of the geomorphic anomaly which is proxy of subsurface structure is visible in the independent component analysis (independent component analysis attempts to decompose a multivariate signal into independent non-Gaussian signals) of satellite data and probable gas seepage zones through the geological fracture (Figure 3)

High resolution Thermal Infrared (TIR) remote sensing (in line with ASTER TIR or better) is useful for determining rock types, structure, besides observing radiant temperatures for effective and near real-time oil well fire monitoring and disaster management. Advanced Image Processing of data from very high spatial resolution optical images (e.g., Cartosat- series, as well as quality data from commercial satellites such as Worldview, GeoEye, etc.) for planning and management of surface infrastructure; automated extraction of features from high quality optical images is useful for pattern detection techniques for risk planning, environmental management and resource monitoring of static installations. National Oil \& Gas pipeline grid can be prepared utilizing 3D terrain models and Satellite imagery can provide high resolution images on periodic basis for monitoring conditions of Oil \& gas pipelines. High resolution photographs in the drone platform can be used to monitor status of long oil \& gas pipelines leaks, making it possible to detect threats to safety and integrity of oil \& gas pipeline at an early stage and enable to take timely remedial actions, thereby saving life, environment, etc. Satellite communication has made it possible to extend reliable, secure communications links which has improved operational efficiency and has also contributed in mitigating emergency situations. Thus Earth observation data in various platforms has immense potential in the petroleum industry.

\footnotetext{
Your subsequent submission with Crimson Publishers will attain the below benefits

- High-level peer review and editorial services

- Freely accessible online immediately upon publication

- Authors retain the copyright to their work

- Licensing it under a Creative Commons license

- Visibility through different online platforms

- Global attainment for your research

- Article availability in different formats (Pdf, E-pub, Full Text)

- Endless customer service

- Reasonable Membership services

- Reprints availability upon request

- One step article tracking system
} 